\title{
MERCÚRIO TOTAL EM SOLOS DE MANGUEZAIS DA BAIXADA SANTISTA E ILHA DO CARDOSO, ESTADO DE SÃO PAULO
}

\author{
Mara Lucia Jacinto Oliveira* e Pablo Vidal-Torrado \\ Departamento de Solos e Nutrição de Plantas, Escola Superior de Agricultura "Luiz de Queiroz", Universidade de São Paulo, \\ CP 9, 13418-900 Piracicaba - SP, Brasil \\ Xosé Luis Otero \\ Departamento de Edafologia e Química Agrícola, Faculdade de Biologia, Universidade de Santiago de Compostela, 15782 \\ Santiago de Compostela, Espanha \\ José Roberto Ferreira \\ Centro de Energia Nuclear na Agricultura, Universidade de São Paulo, 13400-970 Piracicaba - SP, Brasil
}

Recebido em 1/12/05; aceito em 16/8/06; publicado na web em 19/1/07

\begin{abstract}
TOTAL MERCURY IN MANGROVE SOILS OF THE BAIXADA SANTISTA AND CARDOSO ISLAND, SÃO PAULO STATE. Total Hg content in soils of Baixada Santista, affected by different sources of pollution, and Cardoso Island, which is almost free of anthropogenic activities, were determined by CVAAS. To explain the fate of $\mathrm{Hg}$ in the ecosystem, $\mathrm{pH}, \mathrm{Eh}, \mathrm{AVS}, \mathrm{S}_{\text {total }}$ and Total Organic Carbon were also obtained throughout the soil profiles. With the exception of two sampling sites the average content of $\mathrm{Hg}$ in samples obtained for Baixada Santista was $0.34 \pm 0.20 \mathrm{mg} \mathrm{kg}^{-1}$, which was close to the average data at Cardoso Island $(0.30$ $\pm 0.21 \mathrm{mg} \mathrm{kg}^{-1}$ ). Both of them were below the limit established by CETESB $-0.50 \mathrm{mg} \mathrm{kg}^{-1}$.
\end{abstract}

Keywords: mercury; mangrove soils; contamination.

\section{INTRODUÇÃO}

O manguezal é um ecossistema dinâmico de grande importância ecológica e geomorfológica, porém o seu reconhecimento por parte das comunidades científico-sociais é relativamente recente. A localização dos manguezais em áreas protegidas dos litorais, como estuários, baías e lagoas, coincide com áreas de interesse para as comunidades humanas, uma vez que estas são as mais proveitosas para instalação de complexos industriais-portuários e a expansão turístico-imobiliária. Esta infeliz coincidência tem levado, ao longo do tempo, à instalação de distritos industriais, notadamente, pela quantidade de resíduos, efluentes e impactos que geram as atividades industriais e os pólos especializados (petroquímicos e cloroquímicos), degradando ou mesmo erradicando manguezais em grande parte dos litorais dos trópicos em todo o mundo ${ }^{1}$.

O litoral do Estado de São Paulo apresenta áreas ambientalmente degradadas devido à intensa ocupação urbana e instalação de pólos industriais e petroquímicos, freqüentemente desprovidos de tratamento básico adequado. Ações de controle da poluição iniciadas em 1984, e analisadas no final da década de 90, apontam a persistência dos problemas de acumulação dos poluentes nos sedimentos dragados dos canais portuários e, portanto, potencialmente disponíveis à biota aquática, pondo em risco a saúde pública e o equilíbrio ecológico dos ecossistemas costeiros da Baixada Santista ${ }^{2}$.

Dentre os poluentes associados a essas atividades, o mercúrio $(\mathrm{Hg})$ é um metal pesado bastante utilizado no processo produtivo como matéria-prima, produto ou insumo manipulado ou armazenado, portanto presente em efluentes industriais que são despejados diretamente nos rios e manguezais. Neste sentido, são indicadas como principais fontes antropogênicas de contaminação ambiental as indústrias de processamento de metais, produção de cloro-soda, fabri-

*e-mail: maraljo@esalq.usp.br cação de pilhas, lâmpadas fluorescentes, aparelhos de medição e agroquímicos contendo $\mathrm{Hg}$, além de lodo de esgoto ${ }^{2}$.

É importante ressaltar ainda, a contribuição das fontes naturais na emissão e liberação de $\mathrm{Hg}$ para os sistemas ambientais, por meio da volatilização/evaporação do material que compõe a crosta e o manto terrestre, do intemperismo e erosões, sendo menos importante as emissões vulcânicas, degradação de minerais e incêndios florestais ${ }^{3}$. Porém, atualmente, as liberações naturais de $\mathrm{Hg}$ a partir dos solos e da superfície da água são significativamente influenciadas pela deposição prévia proveniente de fontes antropogênicas. A ordem de importância das fontes pela quantidade emitida varia de região para região, dependendo, entre outros, de fatores sócio-econômicos e demográficos ${ }^{4}$.

Após sua entrada nos sistemas ambientais, o Hg apresenta um ciclo complexo no meio natural, compondo as formas inorgânica e/ ou orgânica. Na forma inorgânica, pode ser encontrado sob três diferentes estados de oxidação: o $\mathrm{Hg}$ elementar $\left(\mathrm{Hg}^{0}\right)$, o íon $\mathrm{Hg}$ dimérico $\left(\mathrm{Hg}_{2}{ }^{2+}\right)$, forma pouco estável em sistemas naturais, e o íon mercúrico $\left(\mathrm{Hg}^{2+}\right)$. Na forma orgânica, o íon mercúrico apresenta-se ligado covalentemente a um radical orgânico, sendo o metilmercúrio $\left(\mathrm{CH}_{3} \mathrm{Hg}^{+}\right)$e o dimetilmercúrio $\left(\left(\mathrm{CH}_{3}\right)_{2} \mathrm{Hg}\right)$ os mais comuns. Pode ainda combinar-se a ligantes orgânicos naturais, como ácidos fúlvicos e ácidos húmicos. A conversão entre estas diferentes formas de $\mathrm{Hg}$ é a base do complexo padrão de distribuição do elemento em seu ciclo biogeoquímico e de sua magnificação biológica ${ }^{5}$.

A importância de se estudar o $\mathrm{Hg}$ em solos de manguezais é justificada pela elevada toxicidade e potencial de bioacumulação e biomagnificação que este metal apresenta, em associação a um ecossistema naturalmente dinâmico, característica intensificada pelas atividades antropogênicas. As espécies químicas mais tóxicas de $\mathrm{Hg}$ são as orgânicas: metilmercúrio $\left(\mathrm{CH}_{3} \mathrm{Hg}^{+}\right)$e dimetilmercúrio $\left(\left(\mathrm{CH}_{3}\right)_{2} \mathrm{Hg}\right)$. A assimilação destas formas metiladas de $\mathrm{Hg}$ pelo homem pode alcançar $90 \%$ por meio da ingestão de alimentos contaminados, especialmente peixes, que concentram o 
metal até $10^{3}-10^{4}$ vezes em relação à água ${ }^{6}$. O efeito tóxico do metilmercúrio advém da ligação do mesmo a proteínas, bloqueando as atividades enzimáticas, devido à elevada solubilidade em ambientes lipídicos e à sua afinidade pelos átomos de enxofre dos grupos sulfidrila, abundantes no protoplasma ${ }^{7}$.

À frente do problema exposto, é necessário salientar que, apesar de manguezais estuarinos atuarem como filtros para a contaminação com metais pesados, a persistência destes na forma de precipitados constitui uma fonte potencial secundária de contaminação, a partir da redisponibilização promovida por alterações químicas do meio, como pH e potencial de oxidação-redução, ou mesmo alterações físicas, como retrabalhamento da fauna, desmatamento e erosão. Na geoquímica dos sistemas de manguezais, a cada perturbação há perda de elementos do solo, tornando-o menos apto à ação de novos tensores e, por conseqüência, mais vulnerável e com menor capacidade de suporte ${ }^{8}$.

A fim de contribuir para a avaliação do quadro de contaminação ambiental na Baixada Santista e Ilha do Cardoso, e assim possibilitar estudos sistemáticos sobre a potencial toxicidade do $\mathrm{Hg}, \mathrm{o}$ presente estudo constitui um trabalho preliminar que teve por objetivo identificar áreas altamente poluídas, denominadas internacionalmente como "hotspots", determinando os conteúdos totais deste poluente em solos de manguezais.

\section{PARTE EXPERIMENTAL}

A definição das áreas partiu de uma revisão sobre o histórico da contaminação com $\mathrm{Hg}$, baseada em relatórios de monitoramento publicados pela Companhia de Tecnologia e Saneamento Ambiental (CETESB) e pesquisas afins, nos quais foram relacionados o contaminante, no caso o metal pesado $\mathrm{Hg}$, e a possível fonte do contaminante. Neste contexto, foram amostrados 5 perfis de solos de diferentes manguezais da Baixada Santista, além de uma área livre de atividades antrópicas expressivas, o manguezal da Ilha do Cardoso.

\section{Área de estudo}

Os sistemas estuarinos de Santos e São Vicente inserem-se na região metropolitana da Baixada Santista, Estado de São Paulo, caracterizada pelos mais importantes exemplos brasileiros de degradação ambiental por poluição hídrica e atmosférica de origem industrial em ambientes costeiros ${ }^{10}$. Localizada entre as coordenadas $23^{\circ} 40^{\prime} \mathrm{S}$ e $24^{\circ} 06^{\prime} \mathrm{S}$ e $45^{\circ} 45^{\prime} \mathrm{W}$ e $46^{\circ} 45^{\prime} \mathrm{W}$, compreende a planície da Praia Grande, o Estuário de Santos, a Ilha de Santo Amaro, a Planície de Bertioga e as escarpas da Serra do Mar, totalizando uma área de 51.500 ha, com 10.800 ha cobertos pela vegetação de manguezais ${ }^{11}$.

O sistema estuarino-lagunar de Cananéia-Iguape está localizado no extremo sul do Estado de São Paulo, entre as coordenadas 243' $\mathrm{S}$ e $25^{\circ} 10^{\prime} \mathrm{S}$ e $47^{\circ} 30^{\prime} \mathrm{W}$ e $48^{\circ} 05^{\prime} \mathrm{W}$. Este ambiente apresenta $75 \mathrm{~km}$ de extensão e é composto por um complexo sistema de corpos d'água que circundam quatro ilhas: Iguape, Comprida, Cananéia e do Cardoso. Esta região tem importância ecológica bastante relevante, sendo um dos trechos mais estudados do litoral brasileiro, e classificada atualmente como Área de Preservação Ambiental (APA) ${ }^{12}$.

\section{Clima}

O clima da região da Baixada Santista enquadra-se, segundo o sistema internacional de Köppen, nas classificações AF e CFA ${ }^{13}$ : $\mathrm{AF}=$ clima tropical úmido, sem estação seca, sendo a temperatura média do mês mais quente superior a $18{ }^{\circ} \mathrm{C}$. Esta classificação domina toda a região do Litoral Paulista; $\mathrm{CFA}=$ clima mesotérmico úmido sem estiagem, em que a temperatura média do mês mais quente é superior a $22{ }^{\circ} \mathrm{C}$, apresentando no mês mais seco precipitações pluviométricas superiores a $30 \mathrm{~mm}$.

A circulação atmosférica é dominada pela brisa marítima local e pelas massas de ar tropical atlântica e polar. Nas escarpas da Serra do Mar e proximidades predominam dois fluxos de ventos: nordeste, no período noturno, e sudeste, no período diurno. As maiores velocidades de ventos ocorrem no inverno, atingindo valores máximos entre 13 e 15 h e decrescendo após as 19 h. Este comportamento tem grande importância na dispersão de poluentes atmosféricos provenientes das indústrias instaladas nas escarpas ${ }^{14}$.

\section{Relevo}

O termo baixada refere-se ao interespaço de planícies de marés com mangues existentes entre as duas principais ilhas da região, Santo Amaro e São Vicente, e os múltiplos esporões da Serra do Mar ${ }^{15}$.

A Baixada Santista apresenta relevo de agradação, litorâneo e planície costeira, relacionado às planícies de restinga e às planícies marinha, fluvial e intertidal (mangues); são terrenos baixos, mais ou menos planos, próximos ao nível do mar, com baixa densidade de drenagem e padrão meandrante, onde ocorrem cordões (praias e dunas) ${ }^{16}$.

\section{Geologia e geomorfologia}

O relevo litorâneo do Estado de São Paulo até a Serra do Mar reflete os condicionamentos geológicos predominantes, caracterizando-se por compartimentos distintos definidos por uma região de planalto, com feições amorreadas, uma região de serras e escarpas abruptas e uma planície litorânea de sedimentação ${ }^{16}$.

A região da Baixada Santista abrange parte do complexo cristalino do Planalto Atlântico, composto, sobretudo, por formações gnaissicas das escarpas, sustentadas pelos granitos do PréCambriano. É descrita como um modelado revestido por formações superficiais pouco espessas recobertas pelas florestas tropicais, até os sedimentos costeiros quaternários da planície litorânea, de origem flúvio-marinha, com vegetação pioneira herbácea ou arbórea em solos que apresentam, em geral, hidromorfismo ${ }^{16}$.

Os depósitos quaternários de baixadas são derivados da transgressão Cananéia e transgressão Santos holocênica e refletem as mudanças eustáticas e climáticas ocorridas no período ${ }^{17}$. Os sedimentos derivam, além das variações do nível marinho e efeitos tectônicos recentes, de diferentes fontes de areia, de correntes de deriva litorânea e de sistemas ambientais que os retenham em forma de armadilha, como os sistemas estuarinos vegetados por manguezais ${ }^{18}$.

\section{Localização geográfica dos pontos de amostragem}

A delimitação da área de estudo seguiu critérios de distribuição das fontes potenciais de poluição. A localização dos pontos de amostragem $^{19}$ (Figuras 1 e 2) foi determinada de acordo com os principais condicionadores ecológicos do ecossistema de manguezal, sobretudo a influência do regime de marés, as bacias hidrográficas contribuintes e a vegetação característica de mangue.

\section{Caracterização das fontes de poluição}

A CETESB sistematizou registros e dados históricos do lançamento de poluentes, identificando fontes atuais de poluição hídrica, cujos corpos receptores drenam para os ecossistemas marinhos e estuarinos. Também foram identificadas e caracterizadas as fontes potenciais de poluição existentes na região, incluindo terminais portuários, lixões, aterros sanitários, áreas contaminadas pela disposição inadequada de resíduos tóxicos, estações de tratamento de 


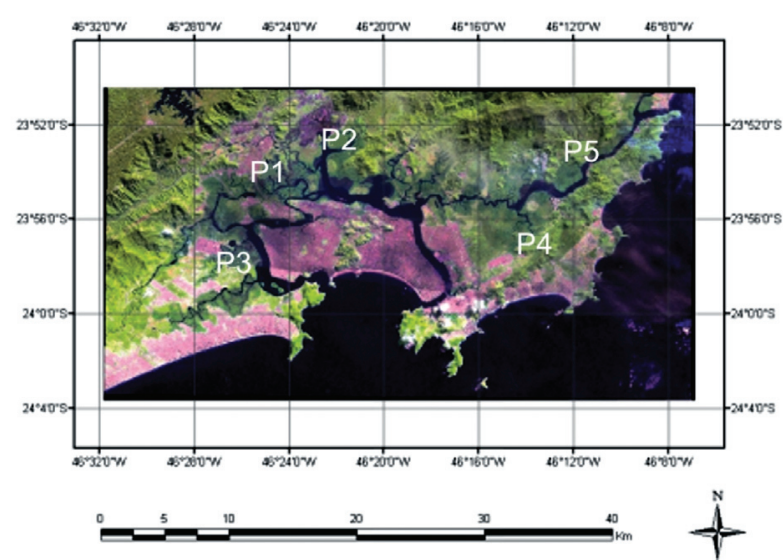

Figura 1. Imagem de satélite e localização dos pontos amostrados na Baixada Santista, Estado de São Paulo

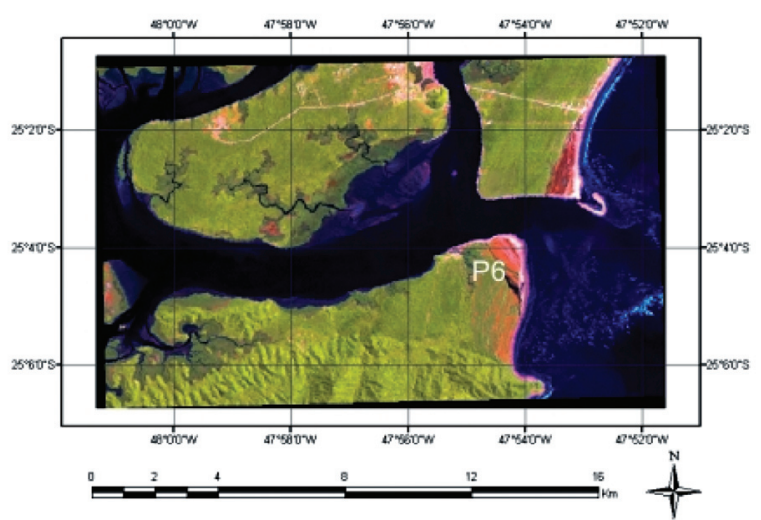

Figura 2. Imagem de satélite e localização do ponto amostrado na Ilha do Cardoso, Estado de São Paulo

águas e esgotos, contribuições difusas e lançamentos in natura de esgotos em canais e rios².

Para definição dos locais de amostragem, foram consideradas as atividades industriais, portuárias, de saneamento básico e áreas contaminadas por resíduos que apresentavam $\mathrm{Hg}$ como produto ou manipulado pela fonte, ou presente como contaminante na matéria-prima, nos insumos ou no produto, ou, ainda, gerado pelo processo produtivo e sistemas de tratamento ${ }^{2}$. Estas relações manguezal versus atividades contaminantes com $\mathrm{Hg}$, são apontadas na Tabela 1.

\section{Amostragem e análises químicas}

Para coleta das amostras semi-deformadas foram utilizados amostrador para solos inundados e tubos de policarbonato, com 5 $\mathrm{cm}$ de d.i. e $50 \mathrm{~cm}$ de comprimento, totalizando três repetições por ponto. No transporte para o laboratório, os tubos foram acondicionados verticalmente em caixas de isopor com gelo, à temperatura de aproximadamente $4{ }^{\circ} \mathrm{C}$. No laboratório, as amostras foram estratificadas em camadas de diferentes espessuras.

$\mathrm{O}$ pH (potencial hidrogeniônico) e o Eh (potencial de reduçãooxidação) foram determinados no campo com aparelhos portáteis, no momento da amostragem. Os valores de $\mathrm{pH}$ foram obtidos com um eletrodo de vidro calibrado com soluções padrão de $\mathrm{pH}$ 4,0 e 7,0 , e os valores de Eh, obtidos com um eletrodo de platina, foram corrigidos pela adição do potencial do eletrodo de referência de calomelano $(+244 \mathrm{mV})$. Os conteúdos de carbono orgânico total (COT) e de enxofre total ( $\mathrm{S}$ total) foram determinados em analisadores elementares, sendo o Leco CNH-1000 para o COT e o Leco 100 S-C 144DR para o S total.

A concentração dos sulfetos voláteis em ácido (AVS: $\Sigma F e S$ amorfo, HS, mackinawita, greigita) foi determinada em triplicata ${ }^{20}$. Os sulfetos da fração AVS foram liberados na forma de $\mathrm{H}_{2} \mathrm{~S}$ em um frasco de reação tampado, a partir de $\sim 1,000 \mathrm{~g}$ de solo úmido com $25 \mathrm{~mL}$ de $\mathrm{HCl} 1 \mathrm{~mol} \mathrm{~L}^{-1}$ (desoxigenado durante 40-50 min), homogeneizado e submetido a um fluxo de nitrogênio, borbulhado lentamente durante $40 \mathrm{~min}$, sob agitação constante. Os sulfetos liberados foram arrastados através do fluxo de $\mathrm{N}_{2}$, até um segundo frasco que continha $25 \mathrm{~mL}$ de solução de acetato de zinco $3 \%$, ficando retidos como $\mathrm{ZnS}$. Transcorrido o tempo de espera, adicionou-se à solução de acetato de zinco, $1 \mathrm{~mL}$ de $\mathrm{H}_{2} \mathrm{SO}_{4}$ concentrado e $4 \mathrm{~mL}$ de reativo de diamida. Este reativo foi preparado adicionando-se 1,6 g de sulfato de 4-amino-N, N-dimetilanilina e 2,4 g de $\mathrm{FeCl}_{3} \cdot 6 \mathrm{H}_{2} \mathrm{O}$ em $100 \mathrm{~mL}$ de $\mathrm{HCl} 50 \%$ (v/v) ${ }^{21}$. A curva padrão foi preparada a partir de um padrão de sulfeto de $1000 \mathrm{mg} \mathrm{kg}^{-1}(7,51 \mathrm{~g}$ $\mathrm{L}^{-1}$ de $\mathrm{Na}_{2} \mathrm{~S} .9 \mathrm{H}_{2} \mathrm{O}$ em água ultrapura desoxigenada por 40-50 min), obtendo-se as concentrações de 0,$00 ; 0,10 ; 0,20 ; 0,40$ e $1,00 \mathrm{mg}$ $\mathrm{kg}^{-1}$ de $\mathrm{S}^{2-}$ em solução de $\mathrm{ZnOAc} 3 \%$. Uma alíquota de $25 \mathrm{~mL}$ de cada padrão foi transferida para tubos de ensaio e na seqüência foram adicionados $1 \mathrm{~mL}$ de $\mathrm{H}_{2} \mathrm{SO}_{4}$ concentrado e $4 \mathrm{~mL}$ de reativo de diamida B. Após $30 \mathrm{~min}$, a concentração de sulfetos foi determinada por colorimetria, utilizando-se espectrofotômetro ultravioleta-visível (UV-VIS) a um comprimento de onda de 670 nm (FEMTO - 600 plus).

A concentração de $\mathrm{Hg}$ total das amostras foi extraída em duplicatas por digestão com $\mathrm{HNO}_{3}: \mathrm{HF}(3: 5 \mathrm{v} / \mathrm{v})$ em forno microondas

Tabela 1. Locais de amostragem e atividades contaminantes

\section{Manguezais Amostrados}

P1 - Rio Cascalho (Cubatão - SP)

P2 - Canal da COSIPA (Cubatão - SP)

P3 - Rio Mariana (São Vicente - SP)

P4 - Rio Crumahú (Guarujá - SP)

P5 - Rio Irirí (Bertioga - SP)

\section{Atividades Relacionadas}

manguezal impactado principalmente por efluentes industriais e esgotos domésticos, além de chorume do lixão do Alemoa manguezal afetado diretamente por efluentes industriais, efluentes de terminais portuários

contribuições de poluentes oriundos de áreas contaminadas por resíduos com organoclorados e metais pesados, bem como é receptor de esgotos in natura

manguezal afetado por esgoto de origem doméstica, proveniente do bairro Morrinhos e Vila Zilda

área impactada com petróleo, proveniente do derramamento de 2,5 milhões de L de petróleo, resultado do rompimento de um oleoduto da Petrobrás, em 1983 manguezal livre de atividades antropogênicas 
$700 \mathrm{~W}^{22}$. As quantificações foram realizadas por espectrometria de absorção atômica com vapor frio (CVAAS - Perkin Elmer FIMS 400) com limite de detecção de $1 \mu \mathrm{g} \mathrm{L^{-1 }}$ de $\mathrm{Hg}$. A precisão analítica dos processos de extração e quantificação foi testada utilizando-se materiais certificados de referência tanto com elevada concentração de $\mathrm{Hg}$ (Montana Soil ref. $2711 \mathrm{Hg}=6,25 \pm 0,19 \mathrm{mg} \mathrm{kg}^{-1}$ ), como com baixa concentração de $\mathrm{Hg}$ (Coal Fly Ash ref. 1333b, Hg $=0,141 \pm 0,019 \mathrm{mg} \mathrm{kg}^{-1}$ ), sendo a porcentagem de recuperação para ambos superior a $93,5 \%$.

Adicionalmente, as variações nas concentrações de $\mathrm{Hg}$ através dos perfis amostrados foram estimadas por meio do fator de enriquecimento (FE). O cálculo dos FE de elementos químicos em solos, sejam eles de procedência natural ou de atividades humanas, é obtido pela normalização das concentrações através de um elemento de referência, como por ex. o alumínio, elemento residual dos processos de intemperização do solo ${ }^{23}$. Este cálculo reduz o efeito da granulometria do solo sobre o conteúdo total de metais pesados, possibilitando a comparação entre amostras de profundidades distintas ${ }^{24,25}$. Além disto, permite estabelecer concentrações de $\mathrm{Hg}$ mais elevadas que a esperada, segundo a base geológica. O cálculo dos FE foi efetuado pela razão (Hg total)/ (Al total) para as amostras, em cada profundidade, e dividida pela mesma relação obtida para a amostra mais profunda do perfil $\operatorname{considerado}^{25}$. O teor de $\mathrm{Al}$ empregado no cálculo foi determinado em espectrofotômetro de chama, no mesmo extrato digerido por solução de $\mathrm{HNO}_{3}: \mathrm{HF}(3: 5 \mathrm{v} / \mathrm{v})$.

\section{RESULTADOS E DISCUSSÃO}

\section{Caracterização dos solos}

Os dados de caracterização dos solos são apresentados na Tabela 2. Os conteúdos de carbono orgânico total oscilaram entre $25,7 \%(\mathrm{P} 4-2,0 \mathrm{~cm})$ e $0,53 \%$ (P6 - 0,5 cm). Os teores mais elevados foram encontrados nas camadas superficiais dos solos, com exceção ao perfil amostrado na Ilha do Cardoso. Em geral, existe uma tendência a diminuir o seu conteúdo com a profundidade ainda que este decréscimo se apresente de modo irregular, devido à variação na distribuição das raízes no solo, concentradas principalmente entre $20-25 \mathrm{~cm}^{26}$. Outra possibilidade pode ser o aporte irregular de matéria orgânica nestes ambientes, devido à variação da taxa de sedimentação. A porcentagem tão reduzida obtida para a camada mais superficial do solo amostrado na Ilha do Cardoso é conseqüência da textura arenosa que o mesmo apresenta ${ }^{26}$.

A oscilação dos valores de $\mathrm{pH}$ para o conjunto das amostras esteve compreendida entre 6,1 (P6 - 22,5 cm) e 7,6 (P2 - $50 \mathrm{~cm})$, estabelecendo condições de $\mathrm{pH}$ moderadamente ácidos ou alcalinos. Estes resultados estão em concordância com trabalhos anteriores para solos submetidos a condições anaeróbias ${ }^{26,27}$.

Os menores valores de $\mathrm{pH}$ estiveram sempre associados à parte superficial do solo. Trabalhos recentes relacionam a acidez das camadas superiores dos solos de manguezais com processos de oxidação dos sulfetos de ferro $(\mathrm{FeS})$, principalmente das frações

Tabela 2. Caracterização dos solos amostrados e conteúdo total de Hg;

\begin{tabular}{|c|c|c|c|c|c|c|c|}
\hline $\begin{array}{l}\text { Profundidade } \\
(\mathrm{cm})\end{array}$ & $\mathrm{pH}$ & $\begin{array}{c}\mathrm{Eh} \\
(\mathrm{mV})\end{array}$ & $\begin{array}{l}\text { COT } \\
(\%)\end{array}$ & $\begin{array}{l}\text { S total } \\
(\%)\end{array}$ & $\begin{array}{l}\text { Al total } \\
(\%)\end{array}$ & $\begin{array}{c}\text { AVS } \\
\left(\mu \mathrm{mol} \mathrm{g} \mathrm{g}^{-1}\right) \\
(\mathrm{n}=3)\end{array}$ & $\begin{array}{c}\mathrm{Hg} \text { total } \\
\left(\mathrm{mg} \mathrm{kg}^{-1}\right) \\
(\mathrm{n}=2)\end{array}$ \\
\hline \multicolumn{8}{|c|}{ Rio Cascalho (P1) } \\
\hline 0,5 & 6,7 & n.a. & 3,57 & 0,65 & 6,31 & 0,07 & 0,76 \\
\hline 3,5 & n.a. & n.a. & 3,36 & 0,43 & 5,78 & 1,60 & 5,65 \\
\hline 7,5 & 6,7 & n.a. & 3,42 & 0,78 & 5,47 & 0,82 & 0,19 \\
\hline 33,5 & 7,0 & n.a. & 3,70 & 0,96 & 4,69 & 0,67 & 0,19 \\
\hline 65 & 7,6 & n.a. & 1,72 & 1,24 & 7,94 & 0,09 & 0,46 \\
\hline \multicolumn{8}{|c|}{ Canal COSIPA (P2) } \\
\hline 0,5 & 7,0 & -12 & 3,07 & 0,80 & 6,33 & 0,02 & 0,63 \\
\hline 3,5 & n.a. & -10 & 2,42 & 0,06 & 6,44 & 0,69 & 0,17 \\
\hline 17,5 & 7,0 & -41 & 2,03 & 1,13 & 8,19 & 0,32 & 0,35 \\
\hline 50 & 7,6 & -55 & 3,50 & 1,82 & 10,44 & 0,66 & 1,64 \\
\hline \multicolumn{8}{|c|}{ Rio Mariana (P3) } \\
\hline 0,5 & 6,6 & -98 & 14,5 & 1,56 & 1,95 & 1,48 & 0,61 \\
\hline 7,5 & 6,8 & 79 & 9,46 & 1,45 & 3,34 & 0,13 & 0,55 \\
\hline 22,5 & 6,7 & 84 & 17,0 & 2,72 & 6,40 & 0,39 & 0,41 \\
\hline 55 & 6,5 & 113 & 13,8 & 3,07 & 7,45 & 0,08 & 0,11 \\
\hline \multicolumn{8}{|c|}{ Rio Crumahú (P4) } \\
\hline 2,5 & 6,7 & 349 & 25,7 & 1,41 & 4,86 & 0,09 & 0,19 \\
\hline 7,5 & 6,4 & 243 & 25,1 & 3,34 & 5,72 & 0,30 & 0,19 \\
\hline 33,5 & 6,9 & 17 & 22,9 & 2,45 & 5,88 & 0,32 & 0,30 \\
\hline 60 & 7,0 & 66 & 17,7 & 2,84 & 7,79 & n.a. & 0,18 \\
\hline \multicolumn{8}{|c|}{ Rio Irirí (P5) } \\
\hline 2,5 & 6,3 & 35 & 16,6 & 1,57 & 7,57 & 0,62 & 0,19 \\
\hline 7,5 & 6,4 & 32 & 10,9 & 2,03 & 6,38 & 0,17 & 0,15 \\
\hline 22,5 & 6,7 & 18 & 4,02 & 1,91 & 7,73 & 0,07 & 0,21 \\
\hline \multicolumn{8}{|c|}{ Ilha do Cardoso (P6) } \\
\hline 0,5 & 6,7 & 115 & 0,77 & 0,10 & 2,99 & 0,01 & 0,42 \\
\hline 1,5 & n.a. & n.a. & 0,96 & 0,12 & 3,31 & $<0,02$ & 0,05 \\
\hline 8,0 & 6,2 & 89 & 1,12 & 0,19 & 4,48 & $<0,02$ & 0,14 \\
\hline 22,5 & 6,1 & -10 & 1,17 & 0,35 & 2,76 & 0,52 & 0,56 \\
\hline 60 & 6,6 & 81 & 1,16 & 0,84 & 4,70 & 0,25 & 0,33 \\
\hline
\end{tabular}

n.a.: não analisado 
mais lábeis, como a fração AVS, favorecida pela alta densidade de raízes presentes no horizonte superior ${ }^{26-28}$.

Em contraste, os valores mais elevados de Eh foram determinados nos $10 \mathrm{~cm}$ superficiais do solo. Atendendo às condições de redução-oxidação, os solos dos manguezais estudados apresentam em superfície predominantemente condições sub-óxicas (Eh entre 100-300 mV), transformando-se em anóxicas com a profundidade $(\mathrm{Eh}<100 \mathrm{mV})$. Nestas condições, em superfície devem predominar os processos redutores dos óxidos e hidróxidos de manganês $(\mathrm{Mn})$ e ferro (Fe) e em profundidade a sulfato-redução deve ser o principal processo de oxidação da matéria orgânica ${ }^{29}$.

$\mathrm{O}$ incremento de $\mathrm{S}$ total determinado em camadas abaixo de 20 $\mathrm{cm}$ de profundidade, devido fundamentalmente à síntese de pirita $\left(\mathrm{FeS}_{2}\right)$ sustenta esta avaliação ${ }^{26-28}$. A fração AVS determinada foi altamente variável, tanto espacialmente como em profundidade, sendo esta variabilidade relacionada ao seu caráter lábil, podendo ser rapidamente oxidada, formando a pirita, segundo as reações (1) e (2)

Oxidação: $\mathrm{FeS}+3 / 2 \mathrm{O}_{2}+\mathrm{H}_{2} \mathrm{O} \longrightarrow \mathrm{Fe}^{2+}+\mathrm{SO}_{4}{ }^{2-}+2 \mathrm{H}^{+}$

Transformação em pirita: $\mathrm{FeS}+\mathrm{SH}_{2} \longrightarrow \mathrm{FeS}_{2}+\mathrm{H}_{2}$

\section{Concentrações de $\mathrm{Hg}$ total}

As concentrações determinadas em algumas camadas dos solos do manguezal do rio Cascalho $\left(5,65 \mathrm{mg} \mathrm{kg}^{-1} \mathrm{de} \mathrm{Hg}-3,5 \mathrm{~cm}\right)$ e canal da COSIPA (1,64 mg kg-1 de $\mathrm{Hg}-50 \mathrm{~cm}$ ) (Tabela 2) foram particularmente altas, em comparação com aquelas presentes nas demais amostras analisadas, superando o Valor de Prevenção estabelecido pela CETESB ${ }^{10}$ para o elemento $\mathrm{Hg}$ em solos $\left(0,50 \mathrm{mg} \mathrm{kg}^{-1}\right)$. Porém, excluindo-se as duas amostras referidas, os valores médios observados para $\mathrm{Hg}$ total em solos de manguezais da Baixada Santista foram de $0,33 \pm 0,20 \mathrm{mg} \mathrm{kg}^{-1}(\mathrm{n}=18)$, similares aos obtidos para a Ilha do Cardoso $\left(0,30 \pm 0,21 \mathrm{mg} \mathrm{kg}^{-1}, \mathrm{n}=5\right)$, local de referência para este estudo, e inferiores ao Valor de Prevenção citado. Em média, a concentração total de $\mathrm{Hg}$ na crosta terrestre é de $0,02 \mathrm{mg} \mathrm{kg}^{-1}$, variando entre $0,02 \mathrm{mg} \mathrm{kg}^{-1}$ para rochas graníticas e $0,45 \mathrm{mg} \mathrm{kg}^{-1}$ para folhelhos $^{31}$. Segundo estudos relacionados à saúde pública ${ }^{32}$, os quais avaliam os efeitos da exposição humana à contaminação, o teor máximo de $\mathrm{Hg}$ recomendado para solos seria $0,15 \mathrm{mg} \mathrm{kg}^{-1}$. É importante salientar que os solos amostrados se encontram em áreas drenadas por canais receptores de fontes diversas de $\mathrm{Hg}$, como efluentes industriais, portuários e domésticos, e são consideradas, portanto, áreas críticas do ponto de vista da exposição humana e ambiental.

A observação dos fatores de enriquecimento com a profundidade (Figura 3) indicam um padrão irregular de distribuição de $\mathrm{Hg}$ nos perfis dos solos amostrados. Exceção a isto encontra-se para o rio Mariana, onde foi verificado um enriquecimento de $\mathrm{Hg}$ nas camadas superficiais do solo. Neste local, a atividade contaminante identificada pela $\mathrm{CETESB}^{2}$ foi a disposição de resíduos, a qual pode constituir uma fonte permanente de contribuição das concentrações de Hg para o ambiente. A distribuição irregular do $\mathrm{Hg}$ nas áreas estuarinas pode estar relacionada às atividades impactantes distintas em cada local, como a dragagem no canal da COSIPA, ou mesmo à influência das marés, determinando uma dinâmica peculiar aos solos em estudo, que modificam as condições do meio e interferem na mobilidade das espécies químicas. Os processos de bioperturbação, desenvolvidos principalmente pela atividade de caranguejos ${ }^{28-33}$, devem também ser considerados, dificultando o estabelecimento de valores de datação e taxas de sedimentação para esses ecossistemas. Essa tendência pode ser visualizada em trabalhos realizados com tal finalidade, que apresentam diferentes taxas de sedimentação para o mesmo perfil de solo e demonstram distorções dos valores de datação do perfil regular em ambientes alterados ${ }^{34}$.
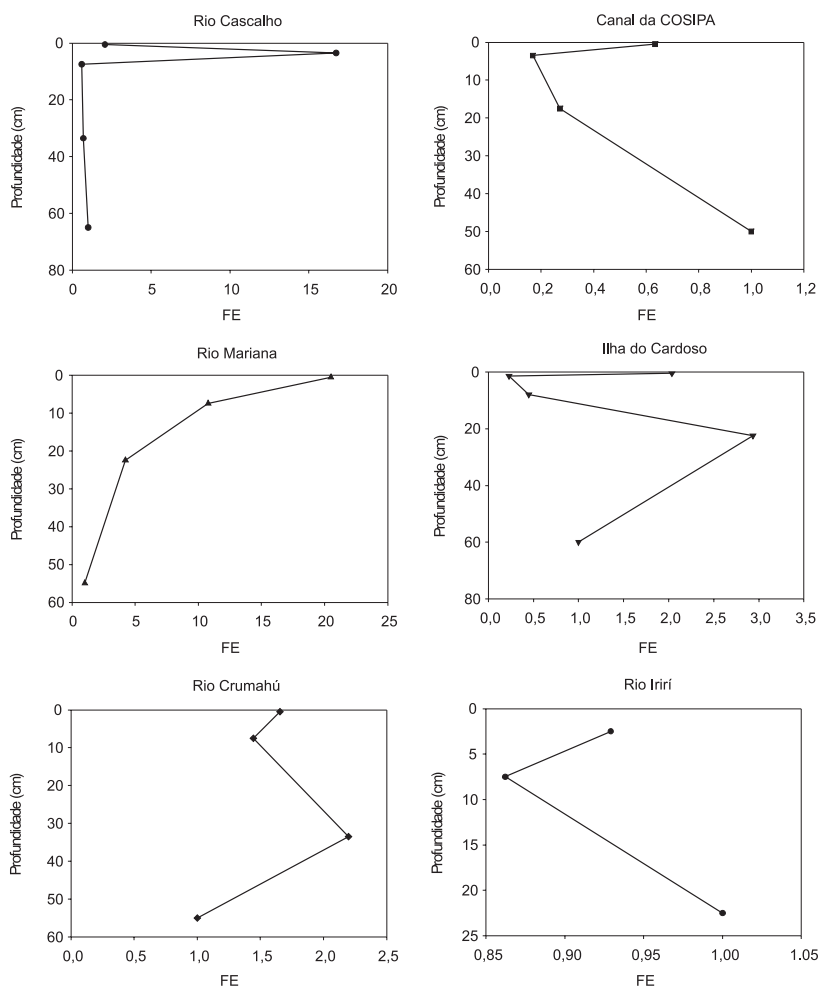

Figura 3. Fatores de enriquecimento do mercúrio calculados em relação à concentração de alumínio para solos de manguezais do rio Cascalho, canal da COSIPA, rio Mariana, rio Crumahú, rio Irirí e Ilha do Cardoso

Os campos de estabilidade para as formas de $\mathrm{Hg}$ em função das variáveis $\mathrm{pH}$-Eh, determinadas nos solos de manguezais amostrados, são apresentados na Figura 4, onde é possível observar que as condições das amostras superficiais favorecem a formação do Hg elementar nesses ecossistemas. A alta volatilidade desta forma de $\mathrm{Hg}$ à temperatura ambiente pode contribuir para sua emissão para a atmosfe$\mathrm{ra}^{35}$ reduzindo, conseqüentemente, sua concentração no solo.

Neste compartimento, os principais componentes que contribuem para a retenção de metais são os óxidos e hidróxidos de Fe e

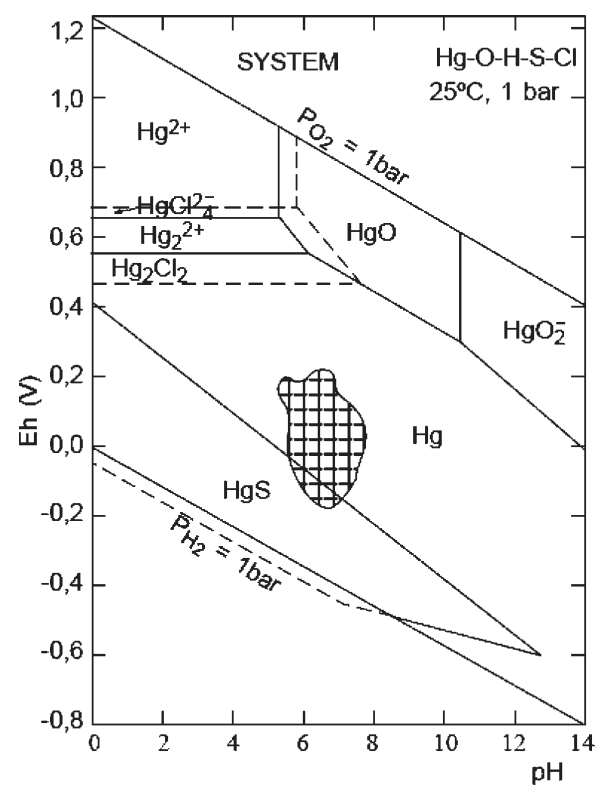

Figura 4. Campos de estabilidade para as formas de $\mathrm{Hg}$ em função das variáveis pH e Eh. Modificado da ref. 36 
Mn, em condições óxicas, e os sulfetos, em meios anóxicos, segundo a reação $(3)^{37}$ :

$\mathrm{Hg}^{2+}+\mathrm{FeS} \longrightarrow \mathrm{HgS}+\mathrm{Fe}^{2+}$

Nos perfis amostrados neste trabalho, os quais apresentaram condições sub-óxicas predominantes em superfície, a concentração de óxidos e hidróxidos de Fe e Mn deve ser baixa, sobretudo as formas mais reativas, menos cristalinas, devido à sua redução pelos microorganismos dos solos. A concentração de Fe reativo (solúvel em $\mathrm{HCl} 1 \mathrm{~mol} \mathrm{~L}^{-1}$ ) encontrado nestes solos (em geral 55,31 \pm $\left.14,7 \mu \mathrm{mol} \mathrm{g}{ }^{-1} ; \mathrm{n}=160\right)^{26}$ foi bastante reduzida. Além disso, as baixas concentrações obtidas para a fração AVS na camada superficial dos solos de manguezais também parecem indicar que o processo de retenção de $\mathrm{Hg}$, segundo a reação (3), terá pouca influência no comportamento do metal. Neste sentido, a redução do sulfato a sulfeto, que ocorre a valores de $\mathrm{Eh}<0 \mathrm{mV}$, alcançando valores máximos a $\mathrm{Eh} \sim-150 \mathrm{mV}^{38}$, se reproduz de forma pouco significativa, desfavorecendo a retenção do $\mathrm{Hg}$ como precipitado $(\mathrm{HgS})$.

\section{CONCLUSÕES}

Com exceção dos dois pontos apresentados com elevadas concentrações de $\mathrm{Hg}$, em camadas superficiais dos perfis amostrados nos pontos P1 (Cascalho) e P2 (COSIPA), os valores médios de concentração de $\mathrm{Hg}$ total obtidos para solos da Baixada Santista foram similares aos obtidos na Ilha do Cardoso e inferiores ao Valor de Prevenção estabelecido pelo órgão ambiental, CETESB.

Nos manguezais as condições de redução-oxidação das camadas superficiais dos solos parecem favorecer a saída deste elemento do sistema, seja por volatilização do $\mathrm{Hg}$ elementar ou porque em condições sub-óxicas a retenção do metal pelo solo é menos eficiente que em ambientes óxicos ou anóxicos.

\section{AGRADECIMENTOS}

À Fundação de Amparo à Pesquisa do Estado de São Paulo (FAPESP), pelo financiamento do projeto de pesquisa e bolsa concedida.

\section{REFERÊNCIAS}

1. Lacerda, L. D.; Ciência Hoje 1984, 3, 63.

2. http://www.cetesb.sp.gov.br/Agua/praias/relatorios.asp, acessada em Outubro 2005.

3. http://www.chem.unep.ch/mercury/Report/GMA-report-TOC.htm, acessada em Agosto 2005.

4. Schroeder, W. H.; Munthe, J.; Atmos. Environ. 1998, 32, 809.

5. Micaroni, R. C. C. M.; Bueno, M. I. M. S.; Jardim, W. F.; Quim. Nova 2000, 23, 487.

6. Figueiredo, B. R.; Minérios e ambiente, Unicamp: Campinas, 2000.
7. Baird, C.; Química ambiental, 2ª ed., Bookman: Porto Alegre, 2002.

8. http://www.bdt.fat.org.br/workshop/costa/mangue/, acessada em Novembro 2005.

9. Myers, N.; Mittermeier, R. A.; Mittermeier, C. G.; Fonseca, G. A. B.; Kent, J.; Nature (London U.K.) 2000, 403, 853; Capobianco, J. P. R.; Ciência Hoje 2000, 27, 11.

10. http://www.cetesb.sp.gov.br/Solo/relatorios.asp, acessada em Junho 2006.

11. Silva, I. X.; Moraes, R. P.; Santos, R. P.; Martins, S. E.; Pompéia, S. L.; Resumos do Simpósio de Ecossistemas da Costa Brasileira, Serra Negra, Brasil, 1994.

12. Bernardes, M. E. C.; Dissertação de Mestrado, Universidade de São Paulo, Brasil, 2001.

13. Lamparelli, C. C.; Mapeamento dos ecossistemas costeiros do Estado de São Paulo, CETESB: São Paulo, 1998.

14. Menezes, G. V.; Poffo, I. R. F.; Eisynk, G. G. J.; Schaeffer-Novelli, Y.; Resumos do Simpósio Sul-Americano de Recuperação de Áreas Degradadas, Foz do Iguaçu, Brasil, 1994.

15. Ab'Sáber, A. N.; Litoral do Brasil, Metalivros: São Paulo, 2003.

16. Rossi, M.; Tese de Doutorado, Universidade de São Paulo, Brasil, 1999.

17. Suguio, K.; Martin, L.; Resumos do International Symposium on Coastal Evolution in the Quaternary, São Paulo, Brasil, 1987.

18. Suguio, K.; Tessler, M. G. Em Restingas: Origem, Estrutura e Processos; Lacerda, L. D.; Araújo, D. S. D.; Cerqueira, R.; Turcq, B., eds.; CEUFF: Niterói, 1984, p. 15.

19. Landsat 7 ETM; INPE: São José dos Campos, 2002. Escala 1:100.000.

20. Kostka, J. E.; Luther III, G. W.; Geochim. Cosmochim. Acta 1994, $58,1701$.

21. Cline, J. E.; Limnol. Oceanogr. 1969, 14, 454.

22. Carral, E.; Puente, X.; Villares, R.; Carballeira, A.; Sci. Total Environ. 1995, $172,175$.

23. Bidone, E. D.; Fernandes, H. M.; Silva Filho, E. V.; dos Santos, L. F. T.; Environ. Technol. 1993, 14, 271; Salminen, R.; Gregorauskiene, V.; Appl. Geochem. 2000, 15, 647.

24. Luoma, S. N. Em Heavy Metals in the Marine Environment; Furness, R. W.; Rainbow, R. S., eds.; CRC Press: Boca Raton, 1990, p. 51.

25. Otero, X. L.; Huerta-Diaz, M. A.; Macías, F.; Environ. Pollut. 2000, 110, 285.

26. Silva, M. L. S.; Tese de Doutorado, Universidade de São Paulo, Brasil, 2005.

27. Ponnamperuma, F. N.; Adv. Agron. 1972, 24, 29.

28. Ferreira, T. O.; Tese de Doutorado, Universidade de São Paulo, Brasil, 2006.

29. Essington, M. E.; Soil and Water Chemistry: An Integrative Approach, CRC Press: Boca Raton, 2004.

30. Rickard, D.; Luther, G. W.; Geochim. Cosmochim. Acta 1997, 61, 135; Otero, X. L.; Calvo de Anta, R.; Macías, F.; Mar. Environ. Res. 2006, 61, 305.

31. Wedepohl, K. H.; Geochim. Cosmochim. Acta 1995, 59, 1217.

32. Hazardous Substances Data Bank; CD Room TOMES CPS TM SYSTEM. Toxicology, Occupatonal Medicine and Environmental Series, Englewwod, Estados Unidos, 2000.

33. Litulo, C.; Estuarine, Coastal Shelf Sci. 2005, 62, 283.

34. Marins, R. V.; Paula Filho, F. J.; Maia, S. R. R.; Lacerda, L. D.; Marques, W. S.; Quim. Nova 2004, 27, 763; Ferreira, J. R.; Tavares, G. A.; Magalhães, C. E.; Silva, N. C.; Taddei, M. H.; Ambio 2003, 32, 47.

35. Martinez-Cortizas, A.; Pontevedra-Pombal, X.; García-Rodeja, E.; NóvoaMuñoz, J. C.; Shotyk, W.; Science 1999, 284, 939.

36. Brookins, D. G.; Eh-pH diagrams for geochemistry, Springer-Verlag: Berlin, 1988.

37. Calmano, W.; Hong, J.; Förstner, U.; Water Sci. Technol. 1993, 28, 223; Di Toro, D. M.; Mahony, J. D.; Hansen, D. J.; Scott, K. J.; Hicks, M. B.; Mays, S. M.; Redmond, M. S.; Environ. Toxicol. Chem. 1990, 9, 1489.

38. Connell, W. E.; Patrick, W. H. Jr.; Science 1968, 159, 86; Patrick, W. H. Jr; Jugsujinda, A.; Soil. Sci. Soc. Am. J. 1992, 56, 1071. 